\title{
El sentido de la tierra. Materialidad, vegetalidad y subjetividad en el texto temprano de Jacques Derrida
}

\author{
Ana Sorin \\ Universidad de Buenos Aires/CONICET
}

Resumen: Derrida dice en más de una oportunidad que la cuestión de los demás vivientes, de lo otro que lo humano, ha inquietado siempre su escritura, aún cuando no fuera tema explícito de sus formulaciones. Este trabajo busca abordar esta aseveración como una ocasión para interrogar si tal inquietud se inscribió de manera semejante en todos los casos, o si acaso a los distintos tópicos, interlocutores y, en suma, texturas que atraviesa la escritura derridiana, no siguen impactos filosóficos relevantes para el enfoque de tal problema. Para ello se reelerá La voz y el fenómeno (1967) a la luz de las principales tesis del plantismo tal como lo desarrollan M. Marder y J. T. Nealon, a sabiendas no obstante que las plantas no suelen constituir los vivientes no humanos a los que se refiere Derrida. En este sentido, y sin pretender mostrar un supuesto solapamiento o develar lo que en verdad Derrida habría querido-decir, la presente investigación busca examinar una serie de herramientas que nos parecen particularmente interesantes para abordar la subjetividad desde una perspectiva postmetafísica.

Palabras clave: Derrida; plantismo; materialidad; subjetividad

Abstract: "The Sense of the Soil. Materiality, Vegetality and Subjectivity in Jacques Derrida's Early Text". Derrida often says that the question of other living beings, i.e., of the other than the human, has always concerned his writing, even when it was not an explicit theme of his formulations. This paper aims to address this assertion as an occasion to question whether such concern was similarly treated in all cases, or if perhaps the different topics, interlocutors and, in short, textures that Derridian writing goes through, do not bring relevant philosophical impacts for the approach of such problem. To do so, The voice and the phenomenon (1967) will be studied through the main thesis of plantism as developed by M. Marder and J.T. Nealon, recognizing nevertheless that plants do not usually constitute the non-human living beings Derrida refers to. In this sense, and without pretending to "reveal what Derrida really meant", this research seeks to examine a series of tools that we find particularly interesting to approach subjectivity from a postmetaphysical perspective.

Keywords: Derrida; plantism; materiality; subjectivity 


\section{Introducción}

La vegetalidad ha estado, desde Grecia, prácticamente al ras de la gradación ontológica. Por un extraño movimiento ha mentado tanto un estrato fundamental que custodia y protege el dominio entero de lo vivo, cuanto un tipo de organismo todavía demasiado pasivo como para revestir un auténtico protagonismo filosófico. Leemos minuciosas descripciones que la competen por parte de Aristóteles y Hegel, pero incluso allí nos parece que no son el fin último de la especulación. Se trata siempre de un modo de vida que adquiere su valía de una cadena que lo excede y que es menester cubrir en orden a ascender a otras cuestiones de mayor importancia.

Siguiendo la estela de trabajos como los de Michael Marder y Jeffrey T. Nealon -que en los últimos años desarrollaron los principales baluartes del plantismo desde una perspectiva postmetafisica-, en el presente trabajo exploraremos el reino vegetal con el fin de interrogar su fecundidad a la hora de discutir la economía de significación tradicional que, como especificaremos, pende de la diferenciación activa entre lo extenso e inerte y la espontaneidad del pneuma (es decir, de los valores dicotómicos en general y de la distinción y jerarquización de cuerpo y alma en particular).

En más de una oportunidad, Jacques Derrida dice que la cuestión de lo otro que lo humano ha inquietado siempre su escritura, aun cuando no fuera tema explícito de sus formulaciones ${ }^{1}$. En este trabajo quisiéramos abordar esta aseveración como una ocasión para interrogar si tal inquietud se inscribió siempre de manera semejante o si acaso a los distintos tópicos, plataformas, interlocutores y, en suma, texturas que atraviesa la escritura derridiana, no siguen impactos filosóficos relevantes para el enfoque de tal problema. En nuestro caso particular, leeremos La voz y el fenómeno (1967) a la luz de las principales tesis del plantismo, a sabiendas que las plantas no suelen constituir

\footnotetext{
1 Cf. Derrida, J., El animal que luego estoy si(gui)endo, Peretti C. y Marciel C. Rodríguez (trads.), Madrid: Trotta, 2008, p. 51. Alli dice que tal cuestión parécele fundamental, y que la ha abordado sea explícita u oblicuamente en todos los filósofos que han cautivado su interés. Al respecto, queremos hacer dos señalamientos: primero, que en estas lineas refiere a Husserl, aludiendo por tanto a los textos que trabajaremos -donde sin lugar a duda este desarrollo es velado-, y segundo, y aún más importante, que es palpable aquí el titubeo de Derrida ante la coincidencia de lo vivo y el animal. Sobre esta indecisión procuramos plantar nuestras elaboraciones.
} 
los vivientes no humanos a los que se refiere Derrida. Sin pretender mostrar un supuesto solapamiento o develar lo que en verdad habría "querido-decir", nuestra investigación está guiada por una serie de herramientas del mentado texto que, quizás hasta el momento inadvertidas, nos parecen particularmente relevantes para abordar la subjetividad desde una perspectiva postmetafisica. Más aun, creemos que el plantismo, por extemporáneo que sea a La voz y el fenómeno, puede ayudarnos tanto a destrabar algunas dificultades del mismo texto como a problematizar la vinculación de la filosofia temprana derridiana con los otros vivientes.

En función de este bosquejo general, emprenderemos el siguiente itinerario: en primer lugar, haremos una introducción somera a la ontología vegetal, anclándonos fundamentalmente en las formulaciones de Michael Marder; en segundo lugar, abordaremos La voz y el fenómeno, reponiendo su horizonte de desarrollo y situando nuestro núcleo problemático de interés, concerniente a los vínculos entre significación, subjetividad y materialidad; finalmente, explicaremos en qué medida el plantismo nos resulta pertinente y particularmente interesante en aras a reinterpretar el armazón conceptual del mentado texto.

\section{Plantae: erección no autotélica}

Durante los últimos años, la atención sobre la vida vegetal ha aumentado al punto incluso de producir lo que algunos no dudaron en llamar un "plant turn"2. Nuestros desarrollos retomarán fundamentalmente las elaboraciones de Michael Marder y Jeffrey T. Nealon, que sentaron las coordenadas de la interpretación postmetafisica de esta prolífica y creciente área de estudio ${ }^{3}$. Plant-

\footnotetext{
2 Myers, N., "Conversations on Plant Sensing: Notes from the Field", en: Nature Culture, 3 (2015), pp. 35-66.

Por sentar solo algunas referencias, The Vegetative Soul: From the Philosophy of Nature to Subjectivity in the Feminine (2002) de Elaine P. Miller elaboró un increíble aporte acerca de las filiaciones en la tradición filosófica entre el vegetal y lo femenino, y Matthew Hall en Plant as Persons (2011) revisa el sitio otorgado a las plantas en distintas culturas y religiones, señalando oscilamientos e instando a tender un "diálogo" entre el humano y las plantas, a las que cabría otorgarles el estatuto de "persona". Por su parte, How Forests Think: Toward an Anthropology Beyond the H uman (2013), de Eduardo Kohn, se plantea como un trabajo al interior de la antropología, crítico de sí misma, y en La vida de las Plantas. Una metafisica de la mixtura (2016), Emanuele Coccia recupera el vegetal como eslabón fundamental de una cosmología filosóficamente atenta al vaivén que es la vida en todas sus dimensiones. En el caso de Michael Marder, su producción relativa al tópico comenzó en 2011, y dentro de un caudal bastante amplio de trabajos cabe destacar Plant-thinking: a Philosophy of Vegetative Life (2013) y Through Vegetal Being (2016), co-escrito con Luce Irigaray. Jeffrey T. Nealon ha seguido su rastro y ofreció una importante contribución con Plant Theory: Biopower and Vegetable Life (2014).
} 
thinking, el principal texto que tendremos de referencia, comprende todas las atribuciones semánticamente opuestas que urdieron el marco de inteligibilidad de la planta a partir del "eslabón débil" althusseriano: importado del leninismo, este sintagma remite al sitio que signa la vulnerabilidad de un sistema entero. Así, que haya sido considerada simultáneamente "pura superficie" y de naturaleza "escondida", o que "vegetación" ampare en su propia etimología sentidos antagónicos (por caso, mientras que el latín "vegetus" recubre vigorosidad, "vegetar" cifra hoy para nosotros una pasividad insoslayable) habla, según Marder, de una existencia renuente a los valores oposicionales.

Un modo de comenzar a aproximarnos a esta caracterización es atender al hecho que la germinación comience literalmente "en el medio" "the space of the in-between", dice Marder) y que, aun cuando eche raíces y crezcan hojas, no sea posible señalar un vértice que pueda oficiar de principio interno de eclosión del vegetal. Sin tal anclaje autopoiético, toda coordenada ("arriba”, "abajo") debe, para ser siquiera significativa, perder su abstracción y recubrir en sí misma "testimonios" del medio. Vistas de esta manera, la acidez del suelo, la presencia de predadores de distinto tipo, la dirección del viento o el radio y caudal de luz no pueden comprenderse como el horizonte sobre el que se recorta una determinada individualidad cerrada, sino como su enclave vital entero en el sentido más radical. Como diría Emanuele Coccia-cuya cosmología atravesada por la "inmersión" dictamina el acoplamiento y la interrelación de todos los seres-, estamos ante una mixtura inerradicable ${ }^{5}$.

En la misma vía de la falta de principio interno de eclosión, Marder y Nealon insisten sobre el carácter no atomístico de la planta: desde el momento en que, como acabamos de explicar, esta está de cabo a rabo orientada al exterior, no conforma jamás un individuo definido separable del resto, y ello en el sentido

\footnotetext{
4 Para ver cómo se desenvuelve esta "paradoja” desde Aristóteles a Hegel, cf. Marder, M., Plantthinking, Nueva York: Columbia University Press, 2013, pp. 31-33.

5 Coccia destina a las plantas un sitio central puesto que, argumenta, el mundo es vegetal antes que animal e incluso "es lo que las plantas han sabido hacer de él": la fotosintesis habría sido primera de hecho y derecho en la tierra, aquello que la hizo habitable para el reino animal. Estar-en-el-mundo, dice, es estar en la tierra, por tanto, respirar y vivir de y con las plantas. Lo que aúna a todos los vivientes y que el reino vegetal propicia es el soplo, "el verdadero logos del mundo" (Coccia, E., La vida de las plantas, Milone, G. (trad.), Buenos Aires: Miño y Dávila, 2017, pp. 32 y 59). Aunque las elaboraciones de Coccia nos resulten interesantes y pertinentes, este trabajo no sigue su línea en particular, precisamente por su inspiración medievalista y heideggeriana, y por su remisión a lo originario. Como sugeriremos en un momento con "For a Phytocentrism to Come" de Marder, antes que ubicar al vegetal en el centro de la existencia (parte de la estrategia de Coccia), nos interesa estudiar cómo la planta desarma todo centro posible, y así plantear la existencia de comunidades transreinos.
} 
más radical ${ }^{6}$. El sol, el agua y lo mineral en general, entre otros compuestos inorgánicos, constituyen su alteridad primera, a la que forzosamente tiende y que delinea su silueta, y sin embargo su acceso a ellos es fundamentalmente no consciente. Este es uno de los principales puntos que vamos a desarrollar en las próximas líneas, puesto que el sintagma clave de la exégesis marderiana es "pensamiento vegetal".

No solo el pensamiento no se yergue aquí como prerrogativa de sujeto alguno sino que, como detalla Marder siguiendo a Francis Ponge, se trata de un pensamiento "pas de tête" . Ahora bien, ¿en qué consiste esto? En un pensar no unidireccional ni apropiativo, que cuestiona la presunta primacía de la abstracción y de lo inteligible, nos apuramos a contestar. Sin embargo, y aunque en la introducción ya dijimos que la existencia de la planta es abordada en aras a discutir la economía de significación tradicional, cómo es esto posible todavía no queda claro. En este punto es interesante ver qué le sucede a la distinción -o mejor "diferenciación", subrayando su carácter de constructoentre alma y cuerpo, en la medida en que el pensamiento ya no mienta una facultad remota y abstracta sino literalmente el crecimiento de la planta (uno de los movimientos que le corresponde, que de hecho se encuentra materialmente amalgamado con su nutrición y reproducción) ${ }^{8}$. Aquí reencontramos la

\footnotetext{
6 El carácter individual o no de las plantas inquieta a las ciencias naturales desde hace muchos siglos: Erasmus Darwin y Alexander Braun decían ya en el siglo XIX, por ejemplo, que un árbol era un "enjambre de plantas" y que el brote era lo único morfológicamente plausible de ser comprendido en términos individuales. Hoy en día distintos científicos continúan opinando que la vida vegetal transita los caminos de lo plural o comunitario (James White, por ejemplo, habla de "metapopulaciones"). Cf. White, J., "The Plant as a Metapopulation", en: Annual Review of Ecology, Evolution, and Systematics, 10 (1979), pp. 109-145 y Clarke, E., "Plant Individuality: a Solution to the Demographer's Dilemma", en: Biology and Philosophy, v. XXIII, 3 (2012), pp. 321-361.

7 Francis Ponge constituye una de las referencias literarias más habituales en el pensamiento de Marder. Desde el momento en que la ontología vegetal discute la presunta asepsia de las elucubraciones filosóficas -leyéndolas material y estéticamente- no puede considerarse la literatura como una fuente supletoria. En este caso en particular, el trabajo incesante sobre la naturaleza allende todo rastro humano, y más aun su remisión al modo de vida vegetal, resultan centrales en la pluma pongiana y acompañan a Marder en muchos de sus desarrollos (además de lo acéfalo, la expresión y la posición vegetal serán centrales en lo que sigue). Cf. Ponge, F., De parte de las cosas, Silva Estrada, A. (trad.), Caracas: Monte Ávila, 1994. Para un estudio de su poesía sensible a estos planteos, cf. Pinson, J.-C., Le matérialisme poétique de Francis Ponge, Seyssel: Champ Vallon, 1995.

8 Contra todas las predicciones del sentido común -filosóficamente sedimentado, podríamos acotar- Marder explica que la planta está en constante movimiento (De Anima estipula cuatro movimientos posibles, a saber, alteración de estado, crecimiento y decaímiento y cambio de posición, y las plantas ostentarian los primeros tres). La particularidad es en todo caso que sus movimientos no responden a una decisión voluntaria sino a su intercambio -"sin intercambio", podríamos acotarmaterial con el medio. Cf. Marder, M., Plant-thinking, pp. 20-28. No repondremos la comprensión
} 
confluencia histórica de notas contradictorias puesto que, en la medida en que carece de fin único y concreto (recordemos, por ejemplo, que dijimos que la planta crecía "en el medio"), este crecimiento ha sido interpretado en términos de una abundancia estéril, demasiado agreste y carente de interés ${ }^{9}$. Lo que a todas luces en términos hegelianos recubre un mal infinito ${ }^{10}$ aquí es recuperado como una "intencionalidad reproductiva" o, mejor -invirtiendo el dictum levinasiano-, como "intencionalidad no conciente" ${ }^{11}$ : esa carencia de fin único es interpretada por Marder como el éxodo de una fuerza material e impersonal resistente a toda coagulación substancial.

griega de la planta, sin embargo baste decir que tanto el Timeo como De Anima muestran, si no extrañeza, perplejidad ante su desenvolvimiento en el mundo, que pende de un crecimiento que no trasluce telos alguno. En ambos casos viene a mentar un modo de vida fundamental, primero más precario. Cf. Platón, Timeo, 76e-77c y Aristóteles, De Anima, 1, 415b-430b.

9 Remitimos a esta noción como categoría filosófica, que puede rastrearse en gran parte de los en los desarrollos biopolíticos contemporáneos. Michael Marder y Gary Francione -uno de los principales referentes del abolicionismo dentro de los estudios animalistas- han discutido acerca del estatuto ético de las plantas, y todo el diámetro de sus desavenencias nos parece pender precisamente de esta categoría de interés. De hecho, al final del debate Francione reenvía a la distinción entre reacción y respuesta (que atrae aparejada las de actividad-pasividad y vidamuerte, comprendiendo a lo realmente vivo como aquello que ostenta una singularidad oculta capaz de tener, precisamente, intereses). Cf. Columbia University Blog Press, Michael Marder and Gary Francione Debate Plant Ethics (http://www.cupblog.org/2012/06/05/marder-andfrancione-debate-plant-ethics/), 5 de junio, 2012. Como explicase Foucault en Las palabras y las cosas, la vida como principio abstracto, como fuerza magmática subterránea, no es descubierta sino creada por la biologia en su nacimiento disciplinar. Esta novedad hunde raíces en un cambio en el orden de la representación, en cuanto se desplaza la descripción del semblante visible de las cosas por la explicación de su autorregulación interna (lo que implica pensar en términos de totalidades funcionales cuyos poderes no se resumen en lo superficial). En este sentido, si bien la planta seguirá nombrando el primer eslabón de los seres vivos, se determinará la vida "auténtica" a partir del deseo, es decir, sobre una rejilla zoocéntrica. Dice Foucault: "Entre tanto, la naturaleza clásica había otorgado privilegios a los valores vegetales... el vegetal formaba, para un pensamiento en cuadro, un puro objeto transparente a los secretos generosamente devueltos. A partir del momento en el que los caracteres y las estructuras se escalonan en profundidad hacia la vida -este punto de fuga soberano, indefinidamente alejado, pero constituyente-, es el animal el que se convierte en figura privilegiada" (Foucault, M., Las palabras y las cosas, Frost E.C. (trad.), Buenos Aires: Siglo XXI, 2002, p. 292). Nealon subraya muy bien la relevancia de las elaboraciones foucaulteanas para la ontologia vegetal. ("The First Birth of Biopower", Plant Theory: Biopower and Vegetable Life, California: Stanford University Press, 2014, pp. 1-27).

${ }_{10}$ Como es sabido, el mal o falso infinito sería para Hegel aquel donde su infinitud se comprende

486 partes extra partes. Dice Hegel de la planta que "menos capaz es aún de calor animal y de sentimientos, ya que la planta no es el proceso de reconducir sus miembros, que son más bien meras partes e incluso individuos, a la simple unidad negativa" (Enciclopedia de las ciencias filosóficas, Valls Plana R. (trad.), Madrid: Alianza Editorial, 2005, §344). Plant-thinking se detiene bastante en Hegel, repasando de qué manera, de acuerdo a la filosofia de la naturaleza esbozada en la Enciclopedia, el crecimiento lineal de las plantas y, en general, su falta de autoafección, se corresponde con su ausencia de alma. (p. 108 y ss.) En todo caso, esa misma carencia es ponderada positivamente por Marder para hacer una lectura postmetafisica.

${ }_{11} C f$. Lévinas, E., "La conciencia no intencional", en: Entre Nosotros, Pardo J.L. (trad.), Valencia: Pre-textos, 2001, pp. 149-160). 
El vegetal trabaja convirtiendo lo inorgánico en orgánico, pero, una vez más, esta labor no mienta ninguna apropiación porque carece tanto de un centro desde el cual traccionar semejante movimiento como de una guarida individual de almacenamiento. En esa misma linea es que hemos dicho que su crecimiento no se corresponde con la consumación de sí-de su identidad, de un télos prefigurado-, sino de una conversación con el medio; extraña cadencia la de esta vida que vive del contacto, de la intermitencia constante de texturas, roces y radiaciones, y que no obstante no precisa su apropiación. En todo caso, la cuestión aquí es precisamente comprender cómo esa heteroafección radical a partir de la cual venimos caracterizando al vegetal no lo convierte en completamente pasivo, pero a su vez en qué sentido ese "trabajo" que lleva a cabo contradice los preceptos habituales a la hora de pensar la actividad (por ejemplo, como consumación de un proyecto, como encuentro de un sujeto con un objeto, etcétera).

Uno de los aspectos más atractivos de esta perspectiva es que la planta, aun cuando sí recibe protagonismo filosófico, no podria de modo alguno instituir un nuevo centro de existencia. Marder recuerda que phuta nombró en griego no solo a la planta sino a todo "ser creciente", y a partir de ahí-en debate explícito ante el zoocentrismo y el biocentrismo ${ }^{12}$ - propone su noción de "fitocentrismo". Según explica en "For a Phytocentrism to Come", este permitiría abordar la vida en su plasticidad, materialidad y relación con lo inorgánico, atendiendo las "comunidades de crecimiento" transespecie e incluso transreino"13.

A los ojos de Nealon y Marder, entonces, aquel eslabón “capaz" de horadar la metafísica y su afán sistemático no opera desde la robustez de lo hercúleo, sino a partir de la plasticidad de lo bajo, de la labor paciente de un rumor inarticulado y casi imperceptible pero constante, de un pensamiento cuya sutileza sortea las tretas de la evidencia. Recién ahora, luego de estas precisiones,

\footnotetext{
${ }^{12}$ Estas posturas son abordadas fundamentalmente por Marder en "For a Phytocentrism to Come" (Environmental Philosophy, v. XI, 2 (2014), pp. 237-252), donde por un lado cuestiona al zoocentrismo por instituir un nuevo criterio demasiado corto para ponderar el estatuto de los vivientes (criterio capacitista, podriamos decir, y donde el humano continúa constituyendo la vara última de medida), y por otro objeta que el biocentrismo, mediante una estrategia homogeneizante, se lance sobre la vida en su abstracción sin dejar sitio para lo extraño (uncanny).

${ }^{13}$ Como hemos dicho, su propuesta se distingue de otras del mismo "plant turn". Se trata de una lógica inversa a la que propone Hall, por ejemplo, cuando éste dice: "Revelando que las plantas poseen varias de las capacidades de sintiencia y mentalidad que tradicionalmente se les ha negado, nuevos descubrimientos científicos animan esta perspectiva... Por lo tanto, desde un punto de vista humano, los diálogos humano-animal deben basarse en permitir a las 'voces' de las plantas ser escuchadas y a su presencia ser sentida" (Hall, M., Plant as Persons, Nueva York: New York University Press, 2011, p. 162, la traducción es nuestra).
} 
adivinamos no estar ya delante de una subsistencia desabrida que yace al sol bajo el propio peso de su redundancia, sino liados con una enredadera trepadora cuyos limites y poderes no llegamos a poder distinguir. Volveremos sobre muchas de estas determinaciones.

\subsection{Parpadeo e instante: indicación}

Antes que ejercer críticas externas, la pluma derridiana suele proceder balanceándose de los textos como de lianas, señalando cómo nunca es realmente seguro que la letra se pliegue, que su cuerpo responda y alcance a decir -o también, que solo diga- lo que le es ordenado. La voz y el fenómeno ${ }^{14}$ introduce en la fenomenología husserliana el tópico de la muerte de la mano de la cuestión del signo, gesto que es menester comprender en términos epocales. Si Derrida comenzó estudiando a Husserl desde un abordaje dialéctico en 1954'15, como bien nota J. Bassas Vila, en la década de 1960 la tendencia francesa muda del pensamiento dialéctico a las "determinaciones diferenciales"16. Derrida mismo se ha encargado en más de una oportunidad de marcar tanto sus deudas cuanto sus desavenencias con el estructuralismo ${ }^{17}$, pero no resulta por ello ocioso comprender La voz y el fenómeno en su contexto de emergencia, ciertamente

\footnotetext{
${ }^{14}$ La voz y el fenómeno vio la luz en 1967, junto a La escritura y la diferencia y De la gramatología, con las que guarda una relación rizomática. Baste refrescar rápidamente la cronología de sus escritos sobre Husserl: en 1954 Derrida escribe, bajo la dirección de Maurice de Gandillac, El problema de la génesis en la fenomenología de Husserl, una tesina para el diplôme de'études supérieures. En el Coloquio de Cerisy-la-Salle de 1959 pronuncia “'Génesis y estructura' y la fenomenologia", y en 1962 traduce y confecciona una extensa introducción a Origen de la geometría que resulta galardonada con el premio Jean Cavaillès de Epistemología. Entre 1961 y 1965 imparte una serie de cursos sobre la fenomenología husserliana en la Sorbonne y la École Normale Supérieure que aún permanecen inéditos. En 1966 se publica "La fenomenología y la clausura de la metafísica", y finalmente, en 1967, ven la luz "La forma y el querer-decir" y el ensayo sobre el que a continuación trabajaremos.

15 Por áspero que resulte este término en sus obras siguientes, hay que señalar que en 1954 "dialéctica" no mienta una Aufhebung sino, más bien, la complicación del origen. En El problema de la génesis, Derrida avanza sobre la filosofia de Husserl rastreando cómo una misma aporía concerniente al vinculo entre hecho y derecho (que en varias oportunidades resume como el intríngulis entre dar cuenta de la génesis del sentido o del sentido de la génesis) se reinscribe a lo largo de toda su obra. En ese contexto, "dialéctica" mienta menos la conciliación de momentos dispares que el tránsito -inevitable y sin coto- entre uno y otro. Su lógica es que, si la sintesis es necesaria, entonces ya es precaria. De hecho, Derrida mismo en su "Advertencia" a El problema de la génesis expresa que la utilización de esta noción está muy cerca de la cuestión del suplemento (tan relevante en su pensamiento posterior). Cf. Derrida, J., El problema de la génesis, Bassas Vila J. (trad.), Salamanca: Sígueme, pp. 9-96.

${ }^{16}$ Bassas Vila, J., "Derrida antes de Derrida. Sobre la escritura y el origen dialéctico de la 'diferencia", en: Derrida, J., El problema de la génesis, p. 317.

${ }^{17} C f$. Derrida, J., "La estructura, el signo y el juego en el discurso de las ciencias humanas", en: La escritura y la diferencia, Peñalver, P. (trad.), Madrid: Anthropos, 2012, pp. 383-409.
} 
atravesado por la cuestión del lenguaje y la diferencia. De todas maneras, podría decirse que este ensayo finalmente aborda de frente las vicisitudes que plantase E. Fink y a las que él viniese remitiendo desde su tesina en 1954: ¿qué sucede con el lenguaje en el seno de las reducciones y descripciones fenomenológicas?

La voz y el fenómeno comienza estudiando las precisiones sobre la noción de signo que introduce Investigaciones Lógicas I. Según dice Husserl, "signo" suele comprenderse de dos modos heterogéneos: como expresión (Ausdruck) y como indicación (Anzeichen). La diferencia entre una y otra acepción redunda en que únicamente la expresión porta Bedeutung, término que Derrida traduce al francés por "vouloir-dire" ("querer-decir"). Más que un preciosismo, esta interpretación subraya que si bien todo signo significa, solo la expresión -en su calidad de signo lingüístico- recubre un sesgo intencional. A partir de estas coordenadas, Derrida remitirá a una serie de "adherencias indicativas" que interrogarán el sitio aparentemente accesorio y periférico de la señal, mostrando cómo la dilación y lo inmotivado en general invaden todos los órdenes de derecho fenomenológicos. A continuación, ofreceremos una breve sistematización de sus desarrollos -selectiva y sin duda reductora- en vistas a delinear el problema que nos compete, a saber, las relaciones habidas entre materialidad, subjetividad y significación en la filosofia temprana de Jacques Derrida.

Husserl admite que la señal goza de mayor extensión y que toda expresión requiere siempre de hecho una capa indicativa, pero, precisamente, tan solo para establecer que la primera no constituye en modo alguno un género del que la otra fuera una simple especie. En "la vida solitaria del alma" (im einsamen Seelenleben) se suspende la ligazón con la exterioridad en general, y sin embargo -o gracias a ello- ahí la expresividad de la expresión encuentra su pureza y cumple ejemplarmente su función sin dilación. Enfoca el sentido (Sinn) fielmente, hilvanándolo en la linealidad de una misma intención expresiva, y es a partir de alli que Derrida sugiere la existencia de cierto "voluntarismo trascendental" en la filosofia husserliana: "La expresión es una exteriorización voluntaria, decidida, consciente de parte a parte, intencional. No hay expresión sin la intención de un sujeto que anime el signo, prestándole una Geistigkeit. En la indicación, la animación tiene dos límites: el cuerpo del signo, que no es un soplo, y lo indicado, que es una existencia en el mundo"18.

Ambos límites son reducidos al mínimo en la expresión. Recordando que, en opinión de Derrida, para Husserl el lenguaje tiene por telos la logicidad

${ }^{18}$ Derrida, J., La voz y el fenómeno, Peñalver, P. (trad.), Valencia: Pre-Textos, 1985, p. 78. 
teórica, todo lo que contribuye materialmente a la comunicación efectiva resulta extrínseco a la expresión: no se deja asir por la intención significante, su opacidad introduce el peligro inerradicable de confusión o tergiversación. Así, por ejemplo, los gestos y ademanes "[n]o quieren decir nada porque no quieren decir nada. En el orden de la significación, la intención expresa es una intención de expresar"19. Es la expresión lo que hace de la palabra, inicialmente un sonido vacuo (análogo al mero Körper), "carne espiritual” (geistige Leiblichkeit)20. Apenas poco antes dice Derrida: "la visibilidad, la espacialidad como tales no podrian sino perder la presencia a sí de la voluntad y de la animación espiritual que abre el discurso. Aquellas son literalmente su muerte"21.

Bajo esta tesitura, la voz deviene un éter diáfano que traduce servilmente al orden del discurso la fisonomía del nóema, convirtiéndolo en infinitamente repetible sin moverse de sí mismo: presencia a sí mismo del sentido y del sentido a la conciencia, que redunda en el "oírse-hablar" como un tipo único de autoafección que, dice Derrida, posibilita toda subjetividad o para sí. El Bedeutung permite que el nóema -componente intencional e irreal, según terminología husserliana algo posterior- sea de cierta manera vivido, vivificado por la conciencia, y ello sin traza alguna de facticidad.

Ahora bien, esta autoafección que venimos desglosando descansa sobre una temporalidad específica, a saber, aquella que concibe el ahora como puntofuente. Explica Husserl en Investigaciones Lógicas: "En el discurso monológico las palabras no pueden servirnos para la función de señalar, notificar la existencia (Dasein) de actos psíquicos, pues semejante señal aquí sería inútil (ganz zwecklos ware), ya que los tales actos son vividos por nosotros en el mismo instante (im selben Augenblick)"22.

Según Derrida, la particularidad es que el valor fenomenológico de la punta del instante como punto-fuente sigue ostentando preeminencia en Lecciones sobre la fenomenología de la conciencia del tiempo inmanente, un texto en teoría más sofisticado y que vendría a abordar el problema del tiempo en toda

\footnotetext{
19 Ibid., p. 81.

20 Este cariz volitivo -que ningún husserliano aceptaría sin posar una ristra de objeciones- es lo que conduce a Derrida a hablar de "voz fenomenológica". Si bien no está explicitado, dificilmente ignorase que Husserl en ningún momento se expida en semejantes términos y, sin embargo, como aduce Leonard Lawlor (Derrida and Husserl, Indiana: Indiana University Press, 2002), la mayoría de sus comentarios al maestro fenomenólogo pendulan al ritmo del debate -relativamente veladode sus filiaciones y diferencias con Hegel.

21 Derrida, J., La voz y el fenómeno, p. 80.

${ }^{22}$ Husserl, E., Investigaciones Lógicas I, García Morente M. y J. Gaos (trads.), Madrid: Alianza Editorial, 2006, p. 242 (§8). Traducción levemente modificada. Las cursivas son nuestras.
} 
su originalidad. Allí se notaría la novedad de Husserl sobre Brentano acerca de la cuestión del tiempo, que consiste en que el fenomenólogo considera que la duración de los objetos proviene de la duración de los actos que los perciben. A partir de ahí, el fenomenólogo busca la estructura -ella misma atemporal-que posibilita esta experiencia inmanente del tiempo. Ello conduce a la elucidación de la conciencia absoluta, cuya composición se divide en protoimpresión (que intenciona el ahora como novedad que ingresa a la conciencia), retención (que tiene por correlato intencional objetos o caracteres de objetos ya sidos) y protensión (que intenciona de manera vacía el porvenir). Dicho esto, Husserl advierte que tales distinciones son abstractas y nada más que analiticas, en cuanto el ahora vivenciado es extenso y pende de la modificación retencional (la protoimpresión deviene retención, luego retención de retención, etcétera, y así logra constituirse el pasado).

Si bien la lectura derridiana de Husserl entera constituye una propuesta arriesgada y discutida, en la cuestión de la temporalidad las aguas se disgregan definitivamente. Por ejemplo, Rudolf Bernet, uno de los mayores referentes en este tópico, argumenta que la concepción husserliana del tiempo sortea los prejuicios metafísicos habituales, precisamente en cuanto a partir de Lecciones... el ahora viene a amparar una no-presencia ${ }^{23}$. Ahora bien, Husserl mismo acepta que esta "no-presencia" que de hecho es la retención goza aún de cierto estatuto perceptivo ${ }^{24}$ y ello es precisamente lo que disimula, a juicio de Derrida, la preeminencia del ahora actual. En todo lo que continúa distinguiendo activamente en la ingeniería husserliana la retención de la representación, el ahora actual (aquí, impresión originaria en su calidad de punto-fuente) sigue operando como centro neurálgico e indeclinable de su temporalidad. Antes que de reponer las diferencias descriptivas básicas (que Derrida tiene en cuenta y que es sencillo señalar: la retención o recuerdo primario es una intención vacía que hace a la más mínima experiencia del tiempo, y la representación es un recuerdo secundario que bien podría corresponder, por ejemplo, al recuerdo de

${ }^{23}$ Cf. Bernet, R., "Is the Present Ever Present?", en: Research in Phenomenologie, 12 (1982), pp. 85-112. Otros comentarios a este aspecto pueden ser encontrados en Zahavi, D., Self-Awareness and Alterity: A Phenomenological Investigation, Evanston: Northwestern University Press, 1999. Por su parte, Hägglund critica estas posturas en "Arche-Writing: Derrida and Husserl”, en: Radical Atheism, California: Stanford University Press, 2008, pp. 50-75.

${ }^{24}$ Dice Husserl: "Pero si denominamos percepción al acto en que todo 'origen' se halla, el acto que constituye originariamiente, entonces el recuerdo primario es percepción. Pues solo en el recuerdo primario vemos el pasado; solo en él se constituye el pasado y por cierto no vicaria sino presentativamente" (Lecciones de fenomenologia de la conciencia interna del tiempo, Serrano de Haro, A. (trad.), Madrid: Trotta, 2002, p. 63). 
un objeto lejano), la apuesta aquí trata de rastrear los criterios que solidifican entre líneas, incluso contra la intención expresa del fenomenólogo.

Amén de las variaciones en sus formulaciones, el funcionamiento de los textos derridianos acerca de Husserl suelen primero acentuar cómo la presunta pasividad que este cree introducir tan novedosamente continúa mentando en verdad cierto voluntarismo, para luego sugerir de qué manera el corazón de su propuesta se encuentra no obstante roída por la amenaza de una pasividad tanto más salvaje. En el caso de La voz y el fenómeno, esta amenaza es el lenguaje, no pudiendo este ser definido a partir de una gramática lógica pura, en la medida en que inevitablemente se enlaza con dimensiones tales como la historia y la intersubjetividad, terminando por rebasar así el radio de poder de la subjetividad trascendental25. En este sentido, La voz y el fenómeno no solo discute la distinción entre expresión e indicación (que tendría por fin erradicar del lenguaje propiamente dicho las asociaciones inmotivadas y todo lo relativo a la gestualidad del cuerpo), sino que señala que el lenguaje baña la subjetividad entera. Para comprender esto conviene tematizar brevemente la noción derridiana de "texto".

En primer lugar, hay que aclarar que esta noción no refiere a la escritura en sentido lato ni se contenta con incluir a la oralidad, acaso envolviendo el horizonte entero de "la verbalidad". Si el famoso dictum "no hay afuera del texto" es tan fundamental, es porque trabaja sobre el origen mismo del sentido. Según Derrida, el sentido no reposa tranquilo en un presente anterior inmodificado al que la significación viniera a adherírsele como una película transparente, sino que, podriamos aventurar, donde hay sentido hay proceso de significación y allí, a su vez, iteración y diseminación. Si un signo tuviera lugar solo una vez y pudiera clausurársele un contexto encima, si ostentase la presunta singularidad del hálito vital (aquel que según la metafísica dirime el sentido de las cosas), redundaría en la insignificancia. Antes que una plurivocidad de hecho - por tanto, reductible-, se trata de una condición de derecho para la significación: lo que llamamos "signo" se inscribe como huella. Dicho

\footnotetext{
${ }^{25}$ Es cierto que, conforme pasan los años, Husserl trabaja cada vez con más profundidad el problema de las sintesis pasivas (en otros términos, el tiempo, la historia y la intersubjetividad). Ello es estudiado con detenimiento por Derrida en El problema de la génesis en la filosofia de Husserl, Introducción a "El origen de la geometria" y "Génesis y estructura' y la fenomenología", y no obstante la "Introducción" de La voz y el fenómeno declara de buenas a primeras que los principales baluartes de Investigaciones Lógicas permanecen incuestionados en su obra futura. Desde esa perspectiva, por más aportes sobre el cuerpo, el tiempo, la intersubjetividad y la historia que Husserl parezca hacer, su propuesta adolece de un logicismo primario. $C f$. Derrida, J., La voz y el fenómeno, p. 39.
} 
esto, según La voz y el fenómeno, el lenguaje (entendido como texto) fractura la sola experiencia del tiempo: la retención no puede realmente distinguirse radicalmente de la representación porque ambas penden de la necesidad de reinscripción. Sería imposible retener un ahora en otro ahora y entretejer la cola retencional si este no fuera inscribible como huella en el sentido más general, es decir, como marca reiterable. Explotando la doble traducción de Augenblick como parpadeo e instante ("hay una duración del parpadeo; y ella cierra el ojo"26), Derrida remarca de qué manera que no haya una plataforma estática de presencia sienta la necesidad de repetición (más adelante, iteración). El movimiento de temporalización trascendental comentado hace un momento se lee aquí, entonces, a partir de la différance, del "devenir tiempo del espacio, devenir espacio del tiempo"27.

La presencia del presente alcanza a constituirse a partir del encadenamiento repetido -digamos espacial- con lo otro de sí, y la autoafección solo emerge a título de huella. Encontramos entonces el "funcionamiento" que sugerimos: si Derrida señala que en Lecciones... la retención aún tiene un carácter activo, es para sugerir inmediatamente que la no-presencia asedia la constitución del tiempo de un modo más radical. El presunto flujo de la experiencia del tiempo se ha fragmentado. El lenguaje lo inunda todo. Sintetiza Derrida: "Que este pliegue sea irreductible en la presencia o en la presencia a sí, que esta huella o esta diferencia sea siempre más vieja que la presencia, y que le procure su apertura, ¿no prohíbe todo eso hablar de una simple identidad consigo mismo 'im selben Augenblick'? ¿Acaso no compromete esto el uso que quiere hacer Husserl del concepto de 'vida solitaria del alma' y por consiguiente, la partición rigurosa entre la indicación y la expresión?”28.

No solo no hay intimidad tal que ahorre la utilización de signos, sino que la relación con el objeto es de mostración indicativa. Así, lo que hace al oírse (intimamente) hablar (enfocar fielmente sentidos pre-expresivos) hunde ahora raíces en el signo, y por tanto en cierta dilación y opacidad.

\subsection{Una humanidad "anodonte", una posthumanidad vegetal}

“¿Qué pasa entonces con la voz y con el tiempo? Si la mostración es la unidad del gesto y de la percepción en el signo, si la significación se asigna al

\footnotetext{
${ }^{26}$ Ibid., p. 119.

${ }^{27}$ Derrida, J. "La différance", en: Márgenes de la filosofia, González Marín, C. (trad.), Madrid: Cátedra, 1994, p. 48.

${ }^{28}$ Ibid., p. 122.
} 
dedo y al ojo... ¿qué pasa con la voz y con el tiempo?”29, pregunta Derrida en el penúltimo capítulo de su escrito. "El espacio, el afuera, el mundo, el cuerpo"30 se inmiscuyen, pero sentimos la tentación de preguntar qué corporalidad o, cuanto menos, qué materialidad habita La voz y el fenómeno. Comprendemos que el hecho que la significación se asigne "al dedo y al ojo" viene a subrayar que ahí donde antes reinaba toda una constelación de significantes relativos a la evidencia (en función de cierta familiaridad de naturaleza inmaterial entre conciencia y sentido), ahora irrumpe el signo en toda su densidad. Sin embargo, recordando que Derrida mismo nos ha instado a interrogar con fruición la especificidad de las metáforas en la filosofia ${ }^{31}$, nos preguntamos si esta escena satisface la radicalidad de los planteos de La voz y el fenómeno. ¿Por qué, si está discutiendo primacía de lo intencional y del alma, aún ancla, aunque sea metafóricamente la significación sobre una corporalidad bien concreta (la del humano o, en el mejor de los casos, del primate)? ¿Y cuál sería el coste filosófico de tal metáfora? En la diatriba con el idealismo que recubre Husserl, ¿nombra el dedo una materialidad lo suficientemente opaca, diseminada y diseminante? ${ }^{32}$

En resumidas cuentas, dudamos si la constelación mirada-dedo no reintroduce acríticamente la "escritura manual-visual" que, dice De la gramatología, posibilita y custodia la noción de ánthropos como la conocemos. Según explica este texto, la mirada y la mano se habrian rendido a la escritura, liberando -en una contracara que no mienta fragmentación sino articulación funcional- el sistema audiofónico para el habla. Tal, especifica, fue el inicio o la posibilidad de la técnica, "de la orientación en general"33. En una referencia que no alcanza a

29 Derrida, J., La voz y el fenómeno, pp. 129-130. Las cursivas son nuestras.

30 Citamos la oración completa: "Es en esta diferencia pura donde se enraíza la posibilidad de todo lo que se cree poder excluir de la auto-afección: el espacio, el afuera, el mundo, el cuerpo, etc. Desde que se admite que la auto-afección es la condición de la presencia a sí, ninguna reducción transcendental pura es posible" (ibid., pp. 140-141).

${ }^{31}$ Cf. Derrida, J., "La mitología blanca", en: Márgenes de la filosofia, pp. 247-311,

32 Abordamos el sintagma "materialidad diseminante" a partir del tratamiento que le debe German E. Di Iorio. Cf. Di Iorio, G.E., "Animalidad y escritura en las fronteras de la filosofia. Una exploración derridiana”, en: Cragnolini, M.B., (comp.), "Qué” o "quién”. Los tránsitos del pensar actual hacia la comunidad de los vivientes, Buenos Aires: La cebra, 2017, pp. 201-221.

${ }^{33}$ Derrida, J., De la gramatología, Del Barco, O. y C. Ceretti (trads.), México: Siglo XXI, 1986, p. 112. Derrida no desarrolla esta afirmación, pero, por poner un ejemplo, podriamos interpretar estas palabras en la línea de El papel del trabajo en la transformación del mono al hombre de Engels, allí donde éste indica que fue el pulgar oponible lo que posibilitó la manualidad, ello al trabajo y ello, a su vez, al hombre (siendo la sofisticación de la mano también producto del trabajo). Cf. Engels, F., El papel del trabajo en la transformación del mono al hombre, Ballesteros M. (trad.), Buenos Aires: Cártago, 1980. En una charla de 1997, Derrida dice que "habría que analizar el mantenimiento del modelo del libro, del liber, de la unidad y de la distribución del discurso, incluso de su paginación en la pantalla, incluso del cuerpo, de los manos y de los ojos 
desglosar, Derrida recuerda a Leroi-Gunrham diciendo que ningún hombre futuro "puede en adelante producirse sin la pérdida de la mano, de la dentadura y, en consecuencia, de la posición erguida. Una humanidad anodonte y que viviese acostada, utilizando lo que le quedara de los miembros anteriores para apoyarlos sobre botones, no es totalmente inconcebible" 34 . Si desde los textos tardíos de Derrida podiamos leer esta solidaridad entre mano, dentadura y posición erguida -que determina el espectro de visión- a partir de la tríada voir-savoir-pouvoir 35 , en esta oportunidad deseamos interrogar en qué medida La voz y el fenómeno, que no se esfuerza sino por acorralar lo que coarta la disponibilidad -técnica, podríamos decir- del sentido, mantiene no obstante indemne su núcleo. Quien señala con el dedo lo hace desde un centro indeclinable e inscribe su alrededor como horizonte; quien señala con el dedo tiene una columna vertebral en el sentido que señalara Leroi-Gunrham ${ }^{36}$; quien señala con el dedo es un quién ${ }^{37}$.

Recuperando los interrogantes que planteásemos en la Introducción, que Derrida siempre haya estado preocupado por lo otro que lo humano no equivale a decir que puedan rastrearse de manera positiva tratamientos específicos ni, menos aun, como sugerimos, que en última instancia esta inquietud se haya inscrito siempre del mismo modo o con la misma perceptibilidad. En La voz y el fenómeno la invasión de la mediatez a raíz del signo y de la rugosidad ${ }^{38}$ y

que éste sigue orientando" ("Materia y memoria”, en: Papel máquina, De Peretti, C. y P. Vidarte (trads.), Madrid: Trotta, 2003, p. 27). Es tal núcleo al que queremos apuntar, esta vez en su texto. ${ }^{34}$ Derrida, J., De la gramatología, p. 113.

35 Cf. Derrida, J., "Octava sesión. 20 de febrero de 2002", en: Seminario La bestia y el soberano: volumen I (2001-2002), De Peretti, C. y D. Rocha (trads.), Buenos Aires: Manantial, 2010, pp. 247-278 y Cragnolini, M.B., "Hospitalidad (con el) animal", Escritura e imagen, Herencias de Derrida Universidad Complutense de Madrid (2011), pp. 313-324

${ }^{36}$ En una pequeña nota al pie de apenas tres líneas a cuento de aquellas palabras de LeroiGunrham, Derrida dice que la "época de la escritura" (interpretamos, de la escritura logofonofalocarnocéntrica) se lee a partir del "estar-en-pie" que trabajase en "Fuerza y significación". Acerca de la columna vertebral señalada hace un momento, unas pocas palabras de aquel texto: "La obra tendría que mantenerse de pie. Pero la obra, en tanto excremento, es solo materia: sin vida, sin fuerza ni forma. Siempre cae y se hunde enseguida fuera de mi. Por esa razón la obra -poética o de otro tipo- no me pondrá nunca de pie. Nunca será en ella donde me eregiré" (Derrida, J., "Fuerza y significación", en: La escritura y la diferencia, Peñalver, P. (trad.), Madrid: Anthropos, 2012, p. 252). Sin querer sobrepasar los limites (más económicos que temáticos, habria que decir) que encuadran el presente trabajo, lo que Derrida marca aquí es cómo Artaud critica la escritura que, "en-pie", se pretende espiritualizada y cree poder domeñar el lenguaje. En su reverso, cierta materialidad de la letra parece alzarse -entendiendo, tal vez, lo escrito como "excreto"- en toda su relieve.

${ }^{37}$ Retomando nuestra nimia referencia a los primates, sin entrar en mayores detalles podemos rastrear esta clase de inspiración en Proyecto Gran Simio. Cf. Singer, P. y P. Cavalieri (eds.), The Great Ape Project, Nueva York: St. Martin's Griffin, 1993.

38 Para comprender la referencia a la rugosidad, traemos las siguientes palabas de Derrida: "El primado óptico o escópico, por global que parezca, descansa siempre, incluso en la fenomenología o en el eidetismo husserliano, en una figura del tacto, en un fundamento háptico" (Derrida, J., 
materialidad del lenguaje es tal que, ciertamente, el mentado "oírse-hablar" no encuentra anclaje fijo. Si bien este texto insiste en la cuestión de la vida para la fenomenología, simultáneamente nos sugiere la cuestión de la muerte como hiato y espaciamiento sobre el que se inscribe todo hálito vital. Sin embargo, quisiéramos plantear que tal vez no sea más que la muerte de la vida que accede al sentido, cuya lengua es lógica y poseedora de la capacidad, antes que nada, de permanecer cerca de sí en una interioridad cerrada. Dicho de otra manera, que quizás solo sea la muerte de la vida -históricamente determinada con insistencia como- humana.

En lo que sigue, nuestra contrapropuesta no buscará proponer otra "parte" que ilustre mejor la trabazón del lenguaje y mancomune más seres vivos, de modo que se haga más extenso su radio de alcance, sino ofrecer una subjetividad otra para pensar la significación. Dicho esto, rescataremos la presentación hecha hace un momento de la ontología vegetal para releer los problemas que nos parece tensan el propio texto. Acaso recogiendo los helechos que han proliferado en sus propias líneas, esto nos permitirá aproximarnos a La voz y el fenómeno no como a la prehistoria de la decostrucción -el período de formación académica más tradicional de Derrida-, sino como un pensamiento aún convocante y feraz. Tal vez sea posible, en la línea de reflexiones de LeroiGunrham, oír algo de aquella (post)humanidad "anodonte".

\subsection{El sentido de la tierra}

Consideremos lo que afirmar Derrida: "Sin embargo, si la vista es ideal, el oído lo es más. Sobrepasa a la vista. A pesar de la idealidad de la luz, y de la mirada, los objetos percibidos por el ojo, por ejemplo, las obras de arte plástico, persisten más allá de la percepción en su existencia sensible, exterior, testaruda; resisten a la Aufhebung, no se dejan, en tanto que tales, en absoluto relevar por la interioridad temporal. Frenan el trabajo de la dialéctica. Es el caso de las obras plásticas y será también sin duda el de la escritura como tal. Pero ya no de la música o del habla. El oído es el sentido más sublime"39.

\footnotetext{
"El otro es secreto porque es otro", en: Papel máquina, p. 329). Si suele haber consenso en que la fenomenología privilegia de la vista (a partir del lugar que le otorga a la evidencia), la opinión derridiana es que esto a su vez se sustenta en el tacto. Más precisamente en este caso, en el ideal del tacto de una superficie lisa y llana sin fisuras. Pero como venimos desarrollando, ello no es posible: no puede extirpársele lo indicativo a la expresión, no hay expresión pura, etcétera. En ese contexto, nuestra remisión a lo rugoso tiene que ver con una materialidad inextricable (y rebelde ante todo planteo eidético, como el husserliano), ahí donde la facticidad del mundo, todo lo supuestamente puesto entre paréntesis por la epojé, resulta de pronto irreductible.

39 Derrida, J., “El pozo y la pirámide”, en: Márgenes de la filosofía, pp. 127-128.
} 
El sentido de la tierra. Materialidad, vegetalidad y subjetividad...

Así dice Derrida en "El pozo y la pirámide", una conferencia de enero de 1968 que estudia la semiología de Hegel y que nos parece profundizar el debate en el que de a poco nos descubrimos inmersos (al menos en la medida en que la aproximación al "oírse-hablar" que acabamos de revisar se yergue claramente través del tamiz de la Aufhebung hegeliana: de alli la atribución que se toma Derrida de hablar de "voz fenomenológica"). Lo que este comentario nos daría a pensar es que, por una extraña torsión, lo que el consabido heliocentrismo habría privilegiado no fue realmente lo visible, sino la diafanidad y autoinmediatez de la luz. Siguiendo la traza de aquellas menciones de La voz y el fenómeno, "lo visible" en el secreto inescrutable de su gravidez ha permanecido impensado e impensable, ha sorteado incluso los poderes de toda sintesis pasiva y mentado la imposibilidad por excelencia de insuflar espiritualidad alguna: lo inmotivado, lo irrelevable e impenetrable por la filosofia. Proponemos, entonces, apuntar a lo visible como al espaciamiento. Es sensato señalar que este es en buena medida más amplio (porque atañe a la noción de texto derridiana antes comentada) y, no obstante, acaso por lo mismo que en su búsqueda de lo ideal la tradición privilegiase el tiempo (faltándole todavía el salto a lo atemporal, pero creyendo poder evadir la textura de lo visible), acaso por las enseñanzas del texto "La mitología blanca" (por lo pronto, que la filosofia es necesariamente metáfora y esta, a su vez, usura de lo que nos es más próximo) ${ }^{40}$, la rugosidad rebelde que blande lo visible se nos aparece fundamental para aproximarnos al espaciamiento. No sin mesura, a través de estas aclaraciones proponemos recuperar cierta noción de materialidad, habida cuenta que Derrida señala en más de una oportunidad su aspereza o desconfianza ante los peligros substancialistas que entrevera (dice que es una "palabra de alto riesgo ontológico") 41 . Esta materialidad sobre la que versa el último fragmento citado y que queremos retener no es nada allende lo perceptible, y sin embargo no coincide punto por punto con lo visible en su calidad sensible (en ese caso, sería conjugable en una experiencia interiorizable).

\footnotetext{
40 "La filosofia sería ese proceso de metaforización que se apodera de sí mismo. Por constitución, la cultura filosófica siempre habrá estado gastada... la usura absoluta del signo. ¿Qué es eso? ¿Y esa pérdida -es decir, esa plusvalía ilimitada- no es lo que prefiere el metafisico, sistemáticamente, al elegir por ejemplo los conceptos con forma negativa, ab-soluto, in-finito, in-tangible, no-ser?" (Derrida, J., "La mitología blanca", en: Márgenes de la filosofia, p. 251).

41 Derrida, J., "La cinta de máquina de escribir", en: Papel máquina, p. 121. Allí remite a cierto “'efecto de materia' sin materia”, vinculado a la noción de acontecimiento textual demaniana, que a su vez él reutiliza. Por su parte, tanto la entrevista "Posiciones" (Posiciones, Arranz M. (trad.), Valencia: Pre-textos, 2014, p. 103) como en "Del materialismo no dialéctico (entrevista con Kadhim Jihad)", en: Culturas, v. LXIX, 3 (1986), pp. III-V) remarca que si bien la deconstrucción a todas luces se yergue contra el idealismo, no por ello la noción de materialidad deviene libre de peligros.
} 
Antes que aludir ahora a un sentido de materialidad primero o más profundo de lo que yace a simple vista -en una retórica harto conocida, que se disculparia con falsa modestia antes de asestar su golpe final-, quisiéramos hacer bien lo contrario. Esta densidad material que hace a lo visible es más exterior y superficial que lo visible y, no obstante, lo mismo que lo hiende, lo saja y lo reduce a un excremento no reciclable y no relevable: el doblez que lo abre a la diseminación. En nuestros desarrollos anteriores presentamos la noción de différance fundamentalmente a propósito de la temporalización trascendental, donde la cresta del presente se tramaba a partir del encadenamiento con lo otro, de cierto "devenir espacio". Ahora toca decir que "espacio" -de acuerdo a la fórmula antes citada, "devenir espacio del tiempo, devenir tiempo del espacio"- no comporta, por su parte, una plataforma estática substancial sino que, antes bien, su "devenir tiempo" lo inscribe siempre ya prófugo de sí.

Para lo que viene queremos traer las siguientes palabras de Marder en Plant-thinking: "Mientras que los humanos recuerdan lo que ha aparecido fenomenalmente en la luz, las plantas mantienen la memoria de la luz misma... Es el hecho mismo o la facticidad de la impresión, de una huella ["imprint"], o mejor, una huella ["ex-print"], que forma el registro de lo que un ser vivo ha experimentado en su vida"42. La noción de huella que sugiere -como "exscripción", podría aducirse ${ }^{43}$ - resalta específicamente de qué manera está a tal punto en inapelable relación con lo otro que permanece exterior, de cabo a rabo material y, más aun, visible. Esto no ha de comprenderse en sentido figurado, puesto que la memoria vegetal yace literalmente en la superficie: en sus hojas y sus tallos es posible advertir la memoria de los otros, y la planta es nada más ese intervalo de fricción e inscripción.

\subsection{Hecho de lianas y hiedra, una memoria de la corteza}

La expresión de los animales es oral o animada, imitada por gestos que se borran unos a otros. La expresión de los vegetales es escrita ${ }^{44}$. El costado sin lugar a dudas más atractivo del plantismo -del que, nos parece, penden

\footnotetext{
42 Marder, M., Plant-thinking, p. 156.

43 Marder refiere explícitamente aquí a Jean Luc Nancy, cuyo pensamiento resulta especialmente convocante en su apuesta. Dado que en nuestro caso particular procuramos ofrecer un tratamiento de la noción de huella en Derrida, y particularmente en La voz y el fenómeno, las disquisiciones sobre su pertinencia, diferencia y herencia (en principio, a todas luces fecundisimas) han debido ser diferidas por motivos económicos. Cf. Nancy, J.-L., Ser singular plural, Tudela Sancho, A. (trad.), Madrid: Arena, 2006.

44 Ponge, F., "Flora y fauna" en De parte de las cosas, p. 17.
} 
su semblante y su fecundidad toda- es la insistencia sobre una subjetividad vacía. Según hemos avistado en "Plantae: erección no autotélica", sin centro neurálgico que pudiera oficiar voluntarismo alguno, la vida vegetal mora entera en los pliegues de la heteroafección.

Reza Plant-thinking: “Utilizando la palabra 'lenguaje' para describir la autoexpresión vegetal en toda su materialidad espacializada, no estoy optando por una metáfora. Lo que propongo en cambio es que la filosofia contemporánea incluya a las plantas en la tradición del tratamiento del lenguaje ni como un medio de comunicación ni como algo exclusivamente humano"45. Según desarrolla Marder a partir de De parte de las cosas, de Ponge, en esta autoexpresión la planta se repite - se calca, se imita a sí misma- en el brotar de las hojas, todas iguales y sin embargo diferantes ${ }^{46}$. La "intencionalidad no consciente" que antes comentamos determina, entonces, que esta autoexpresión (que compele a la planta entera, en cuanto no tiene gestos sino posturas que la requieren por completo) desmadre toda reunión teleológica y, por tanto, que no haya crecimiento vegetal sin diseminación.

Hace un momento señalamos lo espinoso que nos resultaba que luego de desarrollos que a todas luces abonaban por una economía material de significación, y aun pese a los distintos amaines y atenuantes, Derrida redundase en metáforas, si no de llano humanistas, por lo menos antropoides. Creyendo que aquello ocluía gran parte de su radicalidad propusimos dar con una subjetividad otra. Ahora bien, ¿acaso no podríamos remitir aquí a la planta?

Si La voz y el fenómeno subraya básicamente al carácter inerradicable de la indicación incluso en la vida solitaria del alma, la ontología vegetal nos deja no ante una subjetividad que señala con el dedo -como un instrumento, desde un centro indeclinable-, sino que es esa turgencia indicativa, cuyo espesor le

\footnotetext{
45 Marder, M., Plant-thinking, p. 75.

46 Esta autoexpresión repetida y sin anclaje, sin querer-decir, tal vez pueda leerse a la luz de la glosolalia, en cuanto ambas han podido ser comprendidas solo a costo de ser insertadas en una narración teleológicas (la planta como escalón vital fundamental, la glosolalia en muchas culturas a partir de un vínculo divino). Más aun, Derrida nos dice que la glosolalia nos lleva al borde donde la palabra no ha nacido todavía (tomando al borde como esencialmente poroso, interior y exterior), que ya no es grito, pero tampoco todavía discurso: a nuestros ojos esto es así porque el grito sube de las entrañas y el discurso pende del sistema fonológico, es decir, porque ambos nacen de órganos, de cierto interior articulado aún demasiado volitivo para la materialidad que aquí está en juego. La materialidad "superficial" que planta y glosolalia parecieran poner a rodar recubre -en la línea del cuerpo sin órganos artaudiano- un punto de suspensión (interno y externo) que desbarata todos los binomios que conocemos, entre cuerpo y alma, entre sonido y el concepto en el otro: recubre cierto espaciamiento. $C f$. Derrida, J., "El teatro de la crueldad y la clausura de la representación” en: La escritura y la diferencia, p. 328. Cf. Artaud, A., Para terminar con el juicio de dios y otros poemas, Mattoni, S. (trad.), Buenos Aires: Cuenco del plata, 2013.
} 
lleva la vida entera, cuya vida está contaminada con lo otro de sí. O bien, que ya no se define en relación con la recuperación espiritual de sí: es visible "y nada más". No hay secreto y eso nos resulta, sin embargo, terriblemente misterioso. La planta es una turgencia sésil, en la linea que anticipase Leroi-Gunrham y luego apuntásemos en "Fuerza significación".

Dijimos que el dedo venía a mentar la dilación -el punto ciego en la evidencia lógica a la que sirve el lenguaje para Husserl-, pero insistimos en preguntar si la planta no nos permite explotar de manera algo más hábil el temperamento de dicha alusión. Más aun, si la ontología de las plantas y, a su vez, la exscripción vegetal recién señalada, no permite comprender bajo una nueva luz las notas con las que caracteriza Derrida a la huella: "una huella imborrable no es una huella" 47 , asesta bastante seguido. Una huella imborrable, que pusiera punto final al texto, que fuera lo suficientemente propia y no se "espaciara", no sería una huella. La planta, precisamente, no tiene guarida a la que recluirse y depende enteramente de los otros. Adquiere potencia en función de su precariedad.

En particular sobre los desarrollos de La voz y el fenómeno, leer la huella en términos vegetales -como un anudamiento heteroafectado diseminable porque inmotivado, e inmotivado porque superficial, material- nos permite comprender la porosidad que marcase Derrida entre retención y representación, que básicamente acentúa la imposibilidad estructural de señalar un sostén de la temporalidad que permanezca incólume e indiferente ante la concretud de los recuerdos que vendrian a adherírsele ${ }^{48}$. Hemos insistido sobradamente en que a la planta le falta toda unidad capaz de arbitrar una cadencia interna, y en ese sentido es que el tiempo vegetal marcha mediante una repetición de la que nunca es

\footnotetext{
47 Estas mismas palabras se repiten tanto en "Freud y la escena de la escritura" como en "De la economía restringida a la economía general (Un hegelianismo sin reserva)", uno de 1966 y otro de 1967, y compilados en La escritura y la diferencia (p. 315 y p. 365), y luego en "El otro es secreto porque es otro", una entrevista hecha por Antoine Spire en el 2000 y compilada en Papel máquina (p. 343).

${ }_{48}$ Podría sugerirse que en este punto Derrida continúa las reflexiones empezadas en 1954 en $E l$ problema de la génesis en la filosofía de Husserl. Sin lugar a dudas los trece años que median entre un escrito y otro inscriben reconfiguraciones conceptuales relevantes -que atañen tanto a sus puntos de partida cuanto a sus objetivos, y que cubren básicamente el tramo desde una ontología temporal dialéctica a la diseminación de la archiescritura-, y no obstante ya allí Derrida señala de qué manera el Presente Viviente alcanza a labrarse única y necesariamente gracias a una síntesis con lo otro de sí, con una retención que, precisamente por su carácter intencional, introduce subrepticiamente lo real y constituido en el ámbito constituyente de la conciencia. Sus formulaciones tempranas versarán precisamente sobre la fecundidad de esta contaminación de lo trascendental y lo empírico, lo constituyente y lo constituido. Cf. Derrida, J., El problema de la génesis en la filosofía de Husserl, pp. 121-143.
} 
principio ni motor, que no trasluce identidad alguna y que es congruente con cierta "memoria de la corteza"; una memoria que yace en la superficie y que no es sino el testimonio del encuentro con el exterior al que está inextricablemente liada. "La différance vegetal inscribe el tiempo de las plantas directamente en el registro espacial del sentido material", nos explica Marder en esta misma dirección ${ }^{49}$. Dicho de otro modo, y recordando la distinción pongiana del epígrafe, quisiéramos comprender esta opacidad material, esta "materialidad diseminante" que hemos divisado en La voz y el fenómeno, no como el gesto del dedo sino como una posición que compromete entera lo que llamamos subjetividad.

El fitocentrismo -que, señalamos, antes que ubicarse en la trinchera de una presunta ipseidad vegetal, vegetaliza la existencia- nos permite abordar la fractura del querer-decir en términos materiales, explotando el rasgo desacralizante de "lo visible" en La voz y el fenómeno en todas sus dimensiones. "El superhombre es el sentido de la tierra... ¡Yo os conjuro, hermanos míos, permaneced fieles a la tierra y no creáis a quienes os hablan de esperanzas sobreterrenales! Son envenenadores, lo sepan o no"50, clama Zaratustra en su primer discurso al pueblo. Precisamente, el pueblo no entiende sus palabras porque Zaratustra "ha escuchado demasiado a los arroyos y a los árboles"51. Lejos de pretender urdir aquí una interpretación de esta fundamental obra nietzscheana, sí nos interesa ultimar -de manera congruente con nuestros desarrollos- que la ontología vegetal y el "sentido de la tierra" 52 que estamos presentando no recubren una inversión sino una transvaloración. Para que el sentido sea de la tierra, esta ha de disputar lo que "sentido" significa: este fue el movimiento que procuramos rastrear en nuestro tratamiento de La voz y el fenómeno y que creemos que el plantismo nos ayuda a profundizar.

Marder explica: “[D]esde una perspectiva fitocéntrica la conciencia no es reductible a los poderes de la representación abstracta, sino que es coextensiva con una orientación material de la vida a sus objetivos, que varían de acuerdo

\footnotetext{
49 Marder, M., Plant-thinking, p. 112.

50 Nietzsche, F., Así habló Zaratustra, Sánchez Pascual, A. (trad.), Madrid: Alianza Editorial, 2008, p. 36.

52 En la traducción al inglés del Zaratustra, el citado sintagma se traduce por "the sens of the earth". No es lo que sucede en las traducciones españolas o francesas ("le sens de la terre" dice esta última) o en el original alemán ("der Sinn der Erde"), donde la ambigüedad entre el planeta y el sustrato (lo que en inglés distinguiriamos como "earth" y "soil") es palpable. Hemos querido jugar con esta ambivalencia, allí donde desertar de las promesas transmundanas podría leerse como volverse hacia la vegetalidad y descubrir otra economía de vida y de significación.
} 
con las temporalidades y perspectivas de lo viviente"53. Ahora bien, así las cosas, en respuesta a la constelación mirada-dedo, y si el fitocentrismo viene a señalar la plasticidad de la vida en su vértice (in)orgánico, ¿no podríamos decir que la significación se asigna al tallo y al vástago? Nealon opina que "como la différance, la physis consiste en un poder de emergencia que permanece indiferente a ésta o aquélla forma de 'vida', a éste o aquél ser individual o a su mundo: una necesaria condición de (im)posibilidad que (al final, o desde el principio) es totalmente indiferente a cualquier piedra, animal, planta o humano individual"54, y aunque coincidamos con su opinión nos preguntamos si -comprendido lo vegetal a partir del fitocentrismo transreino marderiano, como una subjetividad que no tiene por estandarte un viviente-, más que indiferente, la escritura (l'écriture) no nos recuerda a la plasticidad inmotivada, erecta pero no autotética, protésica del vegetal ${ }^{55}$.

Dice Derrida ya sobre el final de su ensayo: "Para lo que 'comienza' entonces, 'más allá' del saber absoluto, se requieren pensamientos inauditos... En la abertura de esta cuestión, ya no sabemos. Lo que no quiere decir que no sepamos nada, sino que estamos más allá del saber absoluto (y de su sistema ético, estético o religioso) en dirección a aquello a partir de lo que se anuncia y se decide su clausura. Una cuestión tal será legítimamente entendida como que no quiere decir nada, como no perteneciendo ya al sistema del querer-decir"56.

Para el "más allá" del saber absoluto cuyos valores tutorean también la autoafección husserliana, se requieren pensamientos que contrarian todo cuanto creíamos saber acerca de la naturaleza de lo vivo, de la vida y del pensar en los estratos supuestamente más elementales de "lo natural". Pensamientos

\footnotetext{
${ }^{53}$ Marder, M., "For a Phytocentrism to Come", p. 244. La traducción es nuestra.

${ }^{54}$ Nealon, Plant Theory: Biopower and Vegetable life, p. 60.

55 ¿No nos dejan estas reflexiones de cara a Clamor, que debate no sin menor fruición la escritura "de-pie", y que nos dice que "el texto está compuesto de lianas y hiedra"? (Derrida, J., Clamor, De Peretti C. y L. Ferrero Carracedo (coords. de trad.), Madrid: La oficina, 2015, p. 25 B). Sin lugar a dudas esta referencia sobrepasa lo que podemos trabajar aquí, pero no queriamos dejar de subrayar Clamor como un horizonte posible para continuar nuestros desarrollos. No solo secundamos a Nealon cuando le atribuye semejante potencia para pensar la vegetalidad, sino que cómo se articula este tópico en Clamor nos parece (a través de claras variaciones estilísticas y "metodológicas" que no son filosóficamente inocuas) ir bastante en la línea de las reflexiones de La voz y el fenómeno: una de las hebras posibles remite a la cuestión de la firma, alli donde la rúbrica es comprendida como un "féretro vertical" (tal como las celdas, para Genet) cubierto de coronas florales como "pompas fúnebres", que signa la identidad como algo inevitablemente mortal. Por otro lado, "Genet" (apellido que no es el del padre, frente a la familia hegeliana) nombra también, con leves diferencias gráficas, una flor y una raza de caballos. La flor mortuoria que tal vez podriamos decir que es la firma no es ni artificial ni natural, y el Libro -cuyo ideal viene trabajando desde De la gramatología- comparece con ella.

${ }_{56}$ Derrida, J., La voz y el fenómeno, pp. 165-166.
} 
jamás oídos porque no vocalizan nada, a los que probablemente haya que aproximarse con otra cosa que los oídos; pensamientos inauditos, pensamientos vegetales que piensan al ras de su propio cuerpo el sentido de la tierra: la materialidad irrelevable e insoslayable que somos. "Cantaré mi canción para los eremitas solitarios o en pareja; y a quien todavía tenga oídos para oír cosas inauditas (Unerhörtes), a ése voy a abrumarle el corazón con mi felicidad"57, clama Zaratustra en busca de compañeros.

Recibido: 16/04/2018

Aceptado: 12/03/2019

\section{Bibliografia}

Aristóteles, De Anima, Calvo Martínez, T. (trad.), Madrid: Gredos, 1978.

Artaud, A., Para terminar con el juicio de dios y otros poemas, Mattoni, S. (trad.), Buenos Aires: Cuenco del plata, 2013.

Bernasconi, R., “The Trace of Levinas in Derrida”, en: Bernasconi, R. y D. Wood (eds.), Derrida and Différance, Evanston: Northwestern University Press, 1988.

Bernet, R., "Is the Present Ever Present?", en: Research in Phenomenologie, 12 (1982), pp. 85-112.

Campos Salvaterra, V., Violencia y fenomenología, Santiago de Chile: Metales pesados, 2017.

Clarke, E., "Plant Individuality: a Solution to the Demographer's Dilemma", en: Biology and Philosophy, v. XXIII, 3 (2012), pp. 321-361.

Cragnolini, M.B., "Hospitalidad (con el) animal", Escritura e imagen, vol. extra: Herencias de Derrida Universidad Complutense de Madrid (2011), pp. 313-324.

Coccia, E., La vida de las plantas, Milone, G. (trad.), Buenos Aires: Miño y Dávila, 2017.

Derrida, J., Clamor, De Peretti C. y L. Ferrero Carracedo (coords. de trad.), Madrid: La oficina, 2015.

Derrida, J., De la gramatología, Barco O. del y Ceretti C. (trads.), México: Siglo XXI, 1986.

Derrida, J., "Del materialismo no dialéctico (entrevista con Kadhim Jihad)", en: Culturas, v. LXIX, 3 (1986), pp. III-V.

Derrida, J., El animal que luego estoy si(gui)endo, De Peretti, C. y C. Rodríguez Marciel (trads.), Madrid: Trotta, 2008.

Derrida, J., Introducción a "El origen de la geometria", Cohen, D. y A. Zinnot (trads.), Buenos Aires: Manantial, 2000.

Derrida, J., La escritura y la diferencia, Peñalver, P. (trad.), Madrid: Anthropos, 2012.

Derrida, J., La voz y el fenómeno, Peñalver, P. (trad.), Valencia: Pre-Textos, 1985.

Derrida, J., Márgenes de la filosofia, González Marín, C. (trad.), Madrid: Cátedra, 1994.

Derrida, J., Papel máquina, De Peretti C. y P. Vidarte (trads.), Madrid: Trotta, 2003.

57 Nietzsche, F., Asi habló Zaratustra, p. 48. 
Derrida, J., Posiciones, Arranz, M. (trad.), Valencia: Pre-textos, 2014.

Derrida, J., Seminario La bestia y el soberano: volumen I (2001-2002), De Peretti C. y D. Rocha (trads.), Buenos Aires: Manantial, 2010.

Di Iorio, G.E., "Animalidad y escritura en las fronteras de la filosofia. Una exploración derridiana”, en: Cragnolini, M.B. (comp.), “Qué” o “quién”. Los tránsitos del pensar actual hacia la comunidad de los vivientes, Buenos Aires: La cebra, 2017, pp. 201-221.

Engels, F., El papel del trabajo en la transformación del mono al hombre, Ballesteros, M. (trad.), Buenos Aires, Cártago, 1980.

Foucault, M., Las palabras y las cosas, Frost E.C. (trad.), Buenos Aires: Siglo XXI, 2002.

Hägglund, M., "Arche-Writing: Derrida and Husserl", en: Radical Atheism, California: Stanford University Press, 2008.

Hall, M., Plant as persons, Nueva York: New York University Press, 2011.

Hegel, G.W.F., Enciclopedia de las ciencias filosóficas, Valls Plana, R. (trad.), Madrid: Alianza, 2005.

Husserl, E., Investigaciones Lógicas I, García Morente, M. y J. Gaos (trads.), Madrid: Alianza, 2006.

Husserl, E., Lecciones de fenomenologia de la conciencia interna del tiempo, Serrano de Haro, A. (trad.), Madrid: Trotta, 2002.

Lawlor, L., Derrida and Husserl, Indiana: Indiana University Press, 2002. Lévinas, E., "La conciencia no intencional", en: Entre Nosotros, Pardo, J.L. (trad.), Valencia: Pre-textos, 2001.

Marder, M., "For a Phytocentrism to Come", en: Environmental Philosophy, v. XI, 2 (2014), pp. 237-252.

Marder, M., Plant-thinking, Nueva York: Columbia University Press, 2013.

Miller, E., The Vegetative Soul, Nueva York: State University of New York Press, 2002. Myers, N., "Conversations on Plant Sensing: Notes from the Field", en: Nature Culture, 3 (2015), pp. 35-66.

Nancy, J.-L., Ser singular plural, Tudela Sancho, A. (trad.), Madrid: Arena, 2006.

Nealon, J.T., Plant theory: biopower and vegetable life, California: Stanford University Press, 2014.

Nietzsche, F., Así habló Zaratustra, Sánchez Pascual, A. (trad.), Madrid: Alianza Editorial, 2008.

Ponge, F., De parte de las cosas, Silva Estrada, A. (trad.), Caracas: Monte Ávila, 1994.

Platón, Diálogos. Obra completa. Volumen VI: Filebo. Timeo. Critias. Durán, M.A. y F. Lisi (trads.), Madrid: Biblioteca Clásica Gredos, 1992.

Singer, P. y P. Cavalieri (eds.), The Great Ape Project, Nueva York: St. Martin's Griffin, 1993. 504 White, J., "The plant as a metapopulation", en: Annual Review of Ecology, Evolution, and Systematics, 10 (1979), pp. 109-145.

Zahavi, D., Self-Awareness and Alterity: A Phenomenological Investigation, Evanston: Northwestern University Press, 1999. 